\title{
Pentalogy of Cantrell
}

INSERM

\section{Source}

INSERM. (1999). Orphanet: an online rare disease and orphan drug data base. Pentalogy of Cantrell. ORPHA:1335

Pentalogy of Cantrell (POC) is a lethal multiple congenital anomalies syndrome, characterized by the presence of 5 major malformations: midline supraumbilical abdominal wall defect, lower sternal defect, diaphragmatic pericardial defect, anterior diaphragmatic defect and various intracardiac malformations. Ectopia cordis (EC) is often found in fetuses with POC. 